\title{
Stigma-Related Stress and its Correlates among Men with Pedophilic Sexual Interests
}

\author{
Sara Jahnke ${ }^{1,4}$, Alexander F. Schmidt ${ }^{2}$, Max Geradt ${ }^{3}$, and Jürgen Hoyer ${ }^{1}$ \\ ${ }^{1}$ Clinical Psychology and Psychotherapy, Technische Universität Dresden, Germany \\ ${ }^{2}$ Institute for Health and Behaviour, INSIDE Research Unit, University of Luxembourg, \\ Walferdange, Luxembourg \\ ${ }^{3}$ the author is sexually interested in children and co-authoring this article under a pseudonym \\ ${ }^{4}$ To whom correspondence should be addressed at Technische Universität Dresden, Klinische \\ Psychologie und Psychotherapie, Hohe Straße 53, 01187 Dresden, Germany, e-mail: \\ jahnke@psychologie.tu-dresden.de
}

(this preprint has been accepted for publication in Archives of Sexual Behavior) 


\begin{abstract}
Despite decades of research on the adverse consequences of stereotyping and discrimination for many stigmatized groups, little is known about how people with pedophilia perceive and react to stigma. In this article, we present a framework that outlines how stigma-related stress might negatively affect emotional and social areas of functioning, cognitive distortions, and the motivation to pursue therapy, all of which may contribute to an increased risk of sexual offending. We tested our hypotheses in an online survey among self-identified Germanspeaking people with pedophilia $(N=104)$ using a wide range of validated indicators of social and emotional functioning (Brief Symptom Inventory-53, UCLA Loneliness Scale, Emotion Subscale of the Coping Inventory for Stressful Situations, Fear of Negative Evaluation-5, Rosenberg Self-Esteem Scale). Specific risk factors such as self-efficacy, cognitive distortions and the motivation to seek treatment were also assessed. In line with our hypotheses, fear of discovery generally predicted reduced social and emotional functioning. Contrary to our predictions, perceived social distance and fear of discovery were not linked to self-efficacy, cognitive distortions, or treatment motivation. Results were controlled for the effects of confounding variables (e.g, age, educational level, social desirability, relationship status). We critically evaluate the empirical contribution of this study to research on stigma and child sex offenses, including a discussion of the results in light of the potential indirect effects that public stigma may have on the overall risk for sexual offenses.
\end{abstract}

KEY WORDS: stigma; pedophilia; paraphilia; child sexual abuse; social distance 


\section{INTRODUCTION}

In recent years, it has been established that having a pedophilic disorder, that is, a paraphilic disorder with a sexual interest in prepubescent children as its key feature (American Psychiatric Association, 2013; Beier et al., 2009), is among the most despised mental disorders (Feldman \& Crandall, 2007; McCartan, 2010). A rich body of research on diverse stigmatized groups shows that stigmatization is linked to a multitude of negative cognitive, emotional, and behavioral outcomes (for an overview see Hatzenbuehler, 2009), including high-risk sexual behavior (Smolenski, Stigler, Ross, \& Rosser, 2011) that have so far not been studied among people with pedophilia. Based on ideas and concerns from the literature (e.g., Fog, 1992; Okami \& Goldberg, 1992; Seto, 2012) we sought to close this research gap and provide an enhanced perspective on child sexual abuse with a framework for the effects of stigma-related stress among people with pedophilia (Figure 1). The framework aims to delineate the consequences of stigma in terms of psychological functioning, while at the same time showing how it may indirectly affect the risk of sexual offending (but note that these consequences are mediated by people's perception of and reaction to stigma). Therefore, we wanted to test to what degree data from an online sample of self-identified people with pedophilia empirically corroborate our framework.

The term stigma "refer[s] to an attribute that it is deeply discrediting," reducing the individual possessing it "in our minds from a whole and usual person to a tainted, discounted one" (Goffman, 1963, p. 3). People are stigmatized based on attributes such as, for example, mental disorders (Angermeyer \& Dietrich, 2006; Rusch et al., 2005) or sexual orientation (Ahmad \& Bhugra, 2010). Public stigma can be conceptualized on a cognitive, affective, and behavioral level, which many authors refer to as stereotypes, prejudice, and discrimination (Rusch, Angermeyer, \& Corrigan, 2005). Stigmatization has been identified as "a central driver of morbidity and mortality at a population level" (Hatzenbuehler, Phelan, \& Link, 
2013, p. 813) due to the stress and social disadvantage that emerge from it. According to the minority stress theory (Meyer, 2003), hiding a discreditable attribute comes at considerable costs, which have been studied particularly often for the lesbian, gay, and bisexual (LGB) community (Pachankis, 2007). Besides external stressors such as experiences of violence or discrimination, these include expectations of stressful events (and the heightened vigilance that results from it), efforts to conceal the stigma, and the internalization of negative attitudes towards the self (Meyer, 2003). Fearful expectations of rejection and the internalization of discrediting stereotypes are potent sources of stress, which may lead to problems coping with negative emotional states (Hatzenbuehler, 2009) and create or aggravate mental health problems (Meyer, 2003; Pachankis, 2007).

Experiences of people who belong to the LGB community or individuals with a psychological disorder seem relevant for research on stigma consequences for people with pedophilia, as pedophilia is an atypical sexual interest (i.e., less common compared to a heterosexual orientation), that is construed as a mental disorder in modern classification systems (but note that having a sexual interest in children is not in itself pathological). We propose that studying pedophilia from a stigma perspective supports attempts to protect children against child sexual abuse, as we will explain in more detail below (see also Jahnke \& Hoyer, 2013).

\section{Stigmatization and Pedophilic Interest}

Roughly, only between $25 \%$ to $50 \%$ of sexual offenders against children are estimated to exhibit pedophilic preferences (Schmidt, Mokros, \& Banse, 2013), and a number of people with sexual interests in children never commit sexual crimes involving children (Dombert et al., 2015). Nevertheless, pedophilia was the disorder that students reported the highest degrees of social distance towards among more than 40 different mental disorders (with the exception of antisocial personality disorder; Feldman \& Crandall, 2007). In two recent 
surveys, reactions towards people with pedophilia were more negative and stigmatizing in almost all studied domains compared to people who abuse alcohol, sexual sadists, and people with antisocial tendencies (Jahnke, Imhoff, \& Hoyer, 2015). Common stereotyped beliefs include that pedophilia is controllable (in the sense that a person with a dominant sexual interest in children can choose whether to have these interests or not) and extremely dangerous (Jahnke et al., 2015). Consequently, many participants reported anger towards this group and intended to refrain from personal contact on virtually all levels of social interaction (Jahnke et al., 2015). Our framework hypothesizes that the substantial stigma against people with pedophilia might increase the likelihood of problems on an emotional, social, and cognitive level, and decrease their motivation to seek help, even if needed and desired (but note these effects are modulated by people's perception of stigma, and that perceived stigma may not correspond to actual stigmatizing opinions expressed or held by the general public).

\section{Effects of Stigma on Emotional Functioning}

Stigmatized individuals often show higher rates of mental disorders or other emotional problems (Meyer, 2003). Stigma-related stress due to the perception of stigmatization is hypothesized to influence general psychological variables that mediate the association between stigma-related stress and psychological disorders (Hatzenbuehler, 2009). These general factors include low self-esteem (Corrigan, Watson, \& Barr, 2006) and deficits in coping and emotion regulation (Hatzenbuehler, 2009). As the overview in Table 1 shows, people with pedophilia exhibit high rates of mood, anxiety (especially social phobia), and substance disorders, which (among other feasible interpretations such as early psychopathology leading both to pedophilia and current psychopathology) could be interpreted as representing effects of stigma-related stress. Note, however, that these rates are potentially biased since most studies were conducted on offenders in correctional facilities. 
Sexual crimes are often preceded by negative emotions (Pithers, Kashima, Cumming, Beal, \& Buell, 1988) and child sex offenders appear to rely more on inadequate emotionfocused coping strategies like excessive self-preoccupation and fantasizing than non-sexual offenders or other controls (Feelgood, Cortoni, \& Thompson, 2005; Marshall, Serran, \& Cortoni, 2000). People who lack skills to manage negative emotional states may use sex as a powerful, yet often problematic coping mechanism (Marshall et al., 2000). Among other factors, emotional problems and low self-esteem are regarded to play an etiological role in sexual offending (Finkelhor \& Araji, 1986; Seto, 2008; T. Ward \& Beech, 2006). Although meta analyses have shown that a lack of self-esteem is cumulatively not a maintaining factor for sexual reoffending, there are notable exceptions from this general pattern (i.e., studies from the UK report substantial relevant effects on sexual recidivism as opposed to studies from North America or New Zealand [ $d=0.67$ vs. $d=-0.02]$; Mann, Hanson, \& Thornton, 2010). Furthermore, a meta-analysis that specifically focused on risk factors for sexual offending against children (Whitaker et al., 2008) showed that child sexual abusers as compared to non-offenders exhibited higher levels of internalizing behavior problems. Moreover, self-esteem was reduced as compared to sexual offenders with adult victims, nonsexual offenders, or non-offenders (Whitaker et al., 2008). For these reasons, emotional disturbances induced by stigma may indirectly contribute to the risk of sexually abusive behavior by people with pedophilia, as indicated by the finding that sexual offenders show less functional coping strategies than non-offenders (Whitaker et al., 2008).

[Insert Table 1 around here]

\section{Effects of Stigma on Social Functioning}

Secure attachments and social support are closely tied to well-being (Baumeister \& Leary, 1995). In people diagnosed with a psychological disorder, perceived stigma was shown to be associated with more problems regarding social functioning and increased social 
withdrawal (Link, Struening, Rahav, Phelan, \& Nuttbrock, 1997). Facing a hostile, uncomprehending world, many people with pedophilia may see no other choice than to keep their sexual interests a secret. Considering the strategic planning and high level of control over one's verbal and nonverbal expressions required to keep a secret (Lane \& Wegner, 1995), elevated rates of social phobia (e.g., Hoyer, Kunst, \& Schmidt, 2001, Table 1), shyness, and deficient social skills (Wilson \& Cox, 1983) among people with pedophilia are perhaps not a surprising finding. Although loneliness has in general not been shown to be predictive of sexual recidivism $(d=0.09)$, the evidence from a larger study needs also to be taken into account $(d=0.35 ; n=799$ as reviewed in Mann et al., 2010). Moreover, metaanalytic findings have revealed that child sexual abusers suffered from increased levels of general social deficits (particularly loneliness) as well as problems with intimate relationships (Whitaker et al., 2008).

In order to overcome their loneliness, people with pedophilia may prefer socializing with people who share their sexual interests. A number of web communities function as support circles (e.g., the German "Jungsforum”, www.jungsforum.net) by offering an “emotional outlet" (Holt et al., 2010, p. 10) and positive identification models (Fog, 1992). Also, some forums explicitly encourage their members to resist sexual impulses towards children (e.g., the web group "Virtuous Pedophiles", www.virped.org). Despite these constructive efforts, isolated groups of people with pedophilia may encourage each other to start relationships with a desired child or otherways behave in problematic ways (Holt, Blevins, \& Burkert, 2010), which might increase their risk of committing sexual offenses involving children or child pornography.

\section{Effects of Stigma on Cognitive Distortions}

Many men who have sexually offended against children report cognitive distortions concerning their crimes, such as, for instance, that children desire sex with adults and are 
"able to make informed decisions about sexual activities with adults" (T. Ward \& Keenan, 1999, p. 827). Such distorted cognitions are seen as a predecessor of (further) sexual offenses (Abel, Becker, \& Cunningham-Rathner, 1984; T. Ward \& Keenan, 1999). We identified several ways in which public stigma might create or exacerbate these cognitive distortions: As described above, we suppose that most people with pedophilia will go to great lengths to avoid discovery of their sexual interests. At the same time, they are confronted with a lack of role models that could openly point out ways to deal with one's sexuality in a responsible, legally non-problematic way, instead seeing themselves portrayed as "monsters" or "beasts" in the media (West, 2000). Many people with pedophilia therefore might lack sufficient "knowledge of any appropriate script for the paraphilic behaviour that would satisfy" (Fog, 1992, p. 137) them, and instead be prone to develop distorted beliefs about sexual offending. On top of that, hiding pedophilic interests decreases opportunities to talk openly about beliefs regarding sexual involvement with children that they might endorse, especially if these beliefs legitimize such behavior. The likelihood to be confronted with alternative explanations that could be provided by most non-pedophilic (and in many cases also pedophilic, Holt et al., 2010) members of the community is reduced if the person with pedophilia is isolated due to stigmatization.

It is furthermore problematic that some cognitive distortions are not only held by many actual or potential sexual offenders victimizing children, but by a large number of people from the general public as well, such as the belief that people with a sexual interest in children are unable to control their behavior. If people with pedophilia adopt the widespread stereotype that all people who sexually fantasize about children will sexually offend sooner or later, they might feel little motivation to employ helpful strategies to avoid such offenses (T. Ward \& Keenan, 1999). Hence, stigma, especially if leading to withdrawal, might increase the likelihood of a person with pedophilia to adopt problematic cognitions about sex 
with children, and, therefore, this person's sexual offense risk (as indicated by the metaanalytic findings that cognitions minimizing perpetrator culpability or tolerating adult-child sexual activity are a risk factor for child sexual abuse; Whitaker et al., 2008).

\section{Effects of Stigma on the Motivation to Pursue Treatment}

An additional adverse consequence is that people who are suffering from symptoms of a mental disorder sometimes avoid seeking therapy because of potential stigmatization (Vogel \& Wade, 2009). Although a large number of people with pedophilia who see themselves at risk of committing sexual offenses can be reached for preventive measures (Beier et al., 2009), it can be hypothesized that many do not dare to contact mental health experts, because they anticipate negative reactions from the treatment staff. In fact, practitioners in a recent Finnish sample (Alanko, Haikio, Laiho, Jahnke, \& Santtila, 2014) and a sample of German psychotherapists (Stiels-Glenn, 2010) were reluctant to work with this group and, in some instances, reported corresponding negative attitudes. On the other hand, the majority of a self-selected sample of German psychotherapists in training showed comparably positive attitudes towards people with pedophilia, especially after receiving a brief anti-stigma intervention (Jahnke, Philipp, \& Hoyer, 2014). Nevertheless, if a therapist (or a fellow patient) makes an indiscrete remark that reveals the client's sexual interest to a third party, his or her personal safety and important social and professional relationships are compromised. Thus, stigma-related stress might deter this group from seeking help.

\section{The Present Study}

Utilizing the theoretical assumptions delineated above (see also Figure 1), we sought to explore associations between stigma-related stress and different areas of functioning. In particular, we examined self-esteem, emotional coping, and symptoms of clinical disorders (emotional functioning), loneliness (social functioning), self-efficacy related to control of sexual urges towards children and beliefs regarding sexual abuse of children (cognitive 
distortions), as well as the motivation to seek therapy. Participants' fears of being discovered and perceived social distance were assessed as indicators of stigma-related stress.

(Insert Figure 1 about here)

As the Internet has emerged as an important medium for people to share personal information, people with pedophilia have discovered new ways of building communities while remaining relatively safe and anonymous (Holt et al., 2010). Hence, we have decided to conduct the study online, which allowed us to a) guarantee a maximum of anonymity in order to increase the truthfulness of self-reports (Kays, Gathercoal, \& Buhrow, 2012; P. Ward, Clark, Zabriskie, \& Morris, 2012), and b) reach a previously understudied subgroup that is likely to differ systematically from incarcerated offenders (see also Hall \& Hall, 2007; Schaefer et al., 2010). In order to build confidence and reduce inadvertent stigmatization, we collaborated with people with pedophilia involved in online forums for this group, including the third author of the current article, who also helped recruiting participants via forum posts.

\section{METHOD}

\section{Participants}

Data from $N=104$ men from Germany $(18-79$ years old, mean age $=37.30, S D=$ 11.86, 85.6\%) were collected between March, 7 and April, 28, 2014. Among all participants, $16 \%$ were married or living in a relationship with an adult partner, and $84 \%$ had no children. Sixty-four percent had completed the Abitur (comparing to a US college entry exam or high school certificate). The great majority of participants (83\%) was sexually interested solely or mostly in boys, but some reported to be equally attracted to children of both sexes (3\%) or solely or mostly girls (14\%). Sixty-eight percent described themselves as dominantly attracted to children below 12 years. Among those participants who reported other notable sexual interests towards adults (32\%), 52\% were attracted solely or mostly to men, $15 \%$ reported equal attraction to adults of both sexes and $33 \%$ were attracted solely or mostly to 
women beside their attraction to children. Seventy-three percent indicated to have never been convicted for sexual crimes against children (including child sexual abuse and child pornography offenses), and $68 \%$ to have never been in treatment for their pedophilic interests. About half of the sample (51\%) had never participated in a study on pedophilia before.

\section{Procedure}

Participants were invited via advertisements in forums directed at people with pedophilia (www.jungsforum.net, www.krumme13.org; all forums operate on a strictly legal basis, and explicitly prohibit posting of illegal contents such as child pornography). Participation was voluntary and no compensation was offered. The survey started with sociodemographic information followed by the self-report scales in the order described in the Measures subsection. At the end of the questionnaire, participants were asked to recruit other individuals among their social network (snowball sampling). Potential participants with Internet anonymity concerns were encouraged to print out the questionnaire and send it to us without identifying information. One participant used this option.

\section{Measures}

\section{Perceived Social Distance Scale}

The Perceived Social Distance Scale is a modified version of the Social Distance Scale that was used in previous studies to assess stigma against people with pedophilia (Imhoff, 2015; Jahnke et al., 2015; Jahnke et al., 2014), where it displayed high internal consistency ( $\alpha=.82)$ and convergent validity (e.g., $r=.38$ with Right Wing Authoritarianism; Jahnke et al., 2015). Instead of indicating one's own agreement with each item (as in the original form of the scale), we asked participants to indicate how much they believe that the majority of people from Germany would agree with the item (instruction: "The following questions are not about your personal beliefs on the subject. Instead, please indicate how, in 
your belief, most people in Germany would respond to these statements concerning people who are dominantly sexually interested in children, but have never committed a crime. I believe that most people in Germany think that...," followed by six items tapping into social distance, Table 2). Responses were assessed on a 7-point Likert scale ranging from 0 (do not agree at all) to 6 (completely agree).

\section{Fear of Discovery Scale}

People keep secrets because they fear negative consequences for the self (e.g., shame, ostracism) once the concealed information is exposed to other people (Smart \& Wegner, 2000). Fear of discovery is the emotional response elicited by the imagined or real threat of a personal secret being discovered by others. This response is characterized by 1) the subjective experience of fear of the secret being discovered, 2) sympathetic responses (e.g., increased heart rate) to thoughts about the secret being discovered, 3) worrying about the secret being discovered, 4) attempts to prevent others from finding out about the secret, and 5) the subjective appraisal of these reactions as distressful or burdensome. The Fear of Discovery Scale (Table 2, developed by the authors) consists of five subscales that represent the aforementioned aspects with two items each, rated on a Likert-type scale from 0 (do not agree at all) to 6 (completely agree). Participants only received the Fear of Discovery Scale in case they chose "yes" when asked whether they want to keep their sexual interest in children a secret from at least one person (forced choice), and were then instructed to complete the scale with regard to this secret. Only items that achieved a minimum score of 9 on a rating scale ranging from 0 (no content validity) to 10 (high content validity) among three senior scientists from our faculty were used in the final questionnaire. The scale was furthermore pretested in a sample of psychology students $(N=21)$ who were instructed to report their feelings, thoughts, and behaviors with respect to a personal secret of their own choice (such as a shameful aspects of one's body, personality, sexuality, or an experience 
from their past that they want to keep others from knowing) and achieved very high internal consistency scores $(\alpha=.90)$.

Brief Symptom Inventory-53

The Brief Symptom Inventory-53 (original English version by Derogatis and Spencer, 1982, German translation by Franke, 2000) with its nine subscales Somatization, Obsessivecompulsive, Interpersonal sensitivity, Depression, Anxiety, Hostility, Phobic anxiety, Paranoid ideation, and Psychoticism, and its global score is a commonly used instrument in clinical practice and research (Derogatis \& Savitz, 2000). Participants filled out 53 items on a 5-point Likert scale ranging from 0 (not at all) to 4 (very strongly) regarding psychological and physical problems that they might have experienced during the last week. Internal consistency for the German version was high with $\alpha=.96$ for the global severity index (Geisheim et al., 2002). Convergent validity was demonstrated via inter-correlations with established questionnaires such as the Beck Depression Inventory $(r=.74$ for the global severity index), and the scale could be used to reach effect size estimates for CBT among $N=$ 617 patients (Geisheim et al., 2002).

UCLA (University of California, Los Angeles) Loneliness Scale Revised

The UCLA Loneliness Scale revised is a shortened (12 items) German language version (Bilsky \& Hosser, 1998) of Russel, Peplau, and Cutrona's (1980) original UCLA Loneliness Scale. Participants indicated their level of agreement with each item (e.g., "My social relationships are superficial," "I feel isolated from others") on a 5-point Likert scale from 0 (very often) to 4 (never). A later version of the original scale (D. W. Russell, 1996) showed high internal consistency $(\alpha>.89)$ and retest reliability over the course of 1 year $(r=$ .73), as well as acceptable convergent validity, as indicated by correlations with other measures of loneliness and related concepts (e.g., $r=-.56$ for social support satisfaction). In its 12 -item German version, the questionnaire demonstrated similarly high reliability (internal 
consistency $\alpha=.90$, split half reliability $r=.89$; Bilsky \& Hosser, 1998). Correlations between the UCLA loneliness score and sociodemographic variables (e.g., age, living alone vs. living with other people) were significant and indicate the validity of the scale (Bilsky \& Hosser, 1998). In a study conducted with child pornography users and child sex offenders from the German Prevention Project Dunkelfeld, the scale displayed high reliability $(\alpha=.92$, Neutze, Grundmann, Scherner, \& Beier, 2012).

Social Desirability Scale -17

Based on the Social Desirability Scale (Crowne \& Marlowe, 1960), Stöber (1999) developed an updated version to measure tendencies to produce socially desirable (yet unlikely) responses among German-speaking subjects (e.g., "I never hesitate to go out of my way to help someone in trouble"). Answers are given on a binary scale (forced choice between true and false). Stöber's (1999) version of the scale displayed acceptable reliability (internal consistency $\alpha>.72$ and retest reliability $r=.82$ within 4 weeks) and was significantly correlated with an older German translation of Crowne and Marlowe's (1960) scale $(r>.67)$.

\section{Rosenberg Self-Esteem Scale}

The Rosenberg Self-Esteem Scale used in this survey (Ferring \& Filipp, 1996) is a German adaptation from Rosenberg's (1965) original scale. Ten items relating to positive and negative attitudes towards the self (e.g., "On the whole, I am satisfied with myself" vs. "I feel I do not have much to be proud of') are answered on a 4-point Likert scale ranging from 0 (do not agree at all) to 3 (completely agree). Items relating to negative feelings are reversely coded, so that higher (overall) scores represent higher levels of self-esteem. Previous analyses showed high internal consistency $(\alpha>.81)$ and split half reliability $(r>.81$, Ferring \& Filipp, 1996). The scale demonstrated significant correlations with measures of optimism, selfefficacy, and affective-motivational variables (e.g., $r>.54$ for hopelessness, Ferring \& Filipp, 1996). 
Fear of Negative Evaluation - 5

Fear of negative evaluation stands for "the tendency to dread being evaluated unfavorably by others" (Kemper, Lutz, \& Neuser, 2012, p. 343) and represents the cognitive component of social anxiety (Neuser, 2003). Kemper et al. (2012) provided a translated 5item short version of the original 30-item English version (Watson \& Friend, 1969) of the scale. Items included, for example, "I worry that I will say or do the wrong things" and "When I am talking to someone, I worry about what the other person may be thinking about me." A 4-point Likert scale from 0 (almost never correct) to 3 (almost always correct) is used. The German short scale showed an internal validity of $\alpha>.84$ in clinical and nonclinical samples (Kemper et al., 2012). In the 30-item English version version (Watson \& Friend, 1969), a retest reliability of $r=.78$ was achieved. Lending validity to the scale Watson and Friend (1969) found that "individuals high on [fear of negative evaluation] became nervous in evaluative conditions, and seemed to seek social approval" and that the scale "showed correlations with other relevant measures" (p. 456).

\section{Therapy Motivation Scale}

We developed a 4-item measure to assess participants' willingness to seek professional help (e.g., medical doctor or psychologist) during a crisis. Items are displayed in Table 2 and were rated on a 7-point Likert scale ranging from 0 (do not agree at all) to 6 (completely agree). Negatively formulated items were recoded so that higher scores represent a higher therapy motivation.

\section{Bumby Child Molest Scale}

This scale contains a list of beliefs that people who have offended against children might use to legitimize their behavior (e.g., "Sexual activity with children can help the child to learn about sex"), rated on a 4-point Likert scale ranging from 0 (strongly disagree) to 3 (strongly agree, Bumby, 1996). We used a 28-item short German version of the scale 
(Rambow, Elsner, Feelgood, \& Hoyer, 2008). Bumby’s (1996) original scale showed "convergent and discriminative validity, freedom from a socially desirable response bias, and utility in assessing the efficacy of a cognitive restructuring treatment component" (p. 37). The German short scale demonstrated an internal consistency of $\alpha=.96$ among a sample of incarcerated sexual offenders (Gonsior, 2002).

Subscale Emotion-Oriented Coping from the Coping Inventory for Stressful Situations

This subscale assesses a person's tendency to react with emotion, self-preoccupation, and wishful thinking in situations of stress (in contrast to problem-focused approaches, see Endler \& Parker, 1990 for the original version of the scale). We used a modified 8-item German version by Kälin (1995). Items (e.g., "I become very tense”) are rated on a 5-point Likert scale ranging from 0 (very untypical) to 4 (very typical). Internal consistency was demonstrated among child pornography users and child sex offenders with pedophilia ( $\alpha=$ .76) and detected offenders scored higher on emotion-oriented coping than undetected offenders (Neutze et al., 2012).

\section{Coping Self-Efficacy Subscale of the Self-Efficacy Scale Related to Minors}

The Coping Self-Efficacy Subscale assesses beliefs regarding one's capability to control sexual urges in various moods or situations (e.g., "even if a minor wishes to be close to me" or "even if I feel lonely") rated on a 4-point Likert scale from 0 (not at all true) to 3 (exactly true, Neutze et al., 2012). We deleted one item of the original 20-item set ("even if I need several attempts before succeeding"), because it implies a prior loss of control over one's sexual urges. The scale was used among patients with pedophilia from the Berlin Prevention Project Dunkelfeld where it displayed high internal consistency $(\alpha=.94$, Neutze, Seto, Schaefer, Mundt, \& Beier, 2011). Furthermore, Neutze et al. (2011) reported a significant positive correlation with a scale assessing the tendency to use sex with children as a coping strategy $(r=.47)$. 


\section{RESULTS}

A descriptive analysis of participants' responses on perceived social distance, fear of discovery, and therapy motivation can be found in Table 2. In general, participants reported high levels of perceived social distance and fear of discovery. Perceived social distance was notably higher than actual social distance found in public stigma surveys (Jahnke et al., 2015). This bias was particularly large when extremely punitive reactions were concerned. For example, $64 \%$ of the current sample believed that most people in Germany think that non-offending people with pedophilia should better be dead, while only $14 \%$ of the German participants in the aforementioned survey actually agreed to this item (note that comparison data may not be representative; cf. Jahnke et al., 2015). Also, the majority of participants reported to be afraid to be discovered as pedophilic and to experience distress because of it. With regard to therapy motivation, people with pedophilia appeared to be ambivalent (52\% would seek professional help even if it meant that they have to talk about their sexual interests to a stranger, but only $36 \%$ believed that a health care professional would understand their problems).

[Insert Table 2 around here]

We compared participants' scores with data from the average population or other available relevant comparison groups (Table 3). People in the current sample of people with pedophilia that were not incarcerated or recruited from therapeutic groups reported similar levels of psychopathology on the Brief-Symptom Inventory-53 than the ones found among patients with pedophilia in the Berlin Prevention Project Dunkelfeld, which recruits participants seeking therapeutic support, but much higher levels than members of the average population. Moreover, participants showed lower levels of emotion-focused coping than a norm population of young Swiss professionals and patients with pedophilia from the Berlin Prevention Project Dunkelfeld. Compared to the general population, participants in this 
sample did not differ with respect to their scores on the Fear of Negative Evaluation Scale-5 and even showed higher levels of self-esteem than individuals in another ad-hoc sample. On the UCLA Loneliness Scale, people with pedophilia from our sample reported higher levels of social isolation than the average population. Attitudes towards sexual activities with children as assessed by the short form of the Bumby Molest Scale in our sample were far less offense-supportive than among incarcerated pedophilic child sexual abusers. Self-efficacy related to minors was much higher in this online sample of people with pedophilia than among detected and undetected offenders with pedophilia or hebephilia (child sexual or child pornography offenders) from the Berlin Prevention Project Dunkelfeld. Finally, participants in this study did not significantly differ from psychology students with respect to their propensity to give socially desirable responses.

[insert Table 3 around here]

Bivariate intercorrelations (Table 4) showed that perceived social distance was significantly linked only to fear of discovery. Fear of discovery was correlated to lower levels of emotional functioning, that is, higher scores on the Brief-Symptom-Inventory-53, the Fear of Negative Evaluation-5, and the Emotion Scale of the Coping Inventory for Stressful Situations, as well as lower scores on the Rosenberg Self-Esteem Scale (all correlations at least $r=.32)$. Furthermore, there was a significant positive correlation $(r=.44)$ between fear of discovery and (reduced) social functioning as measured by the UCLA Loneliness Scale. Neither the Perceived Social Distance Scale nor the Fear of Discovery Scale was significantly linked to the Bumby Scale or the Coping Self-Efficacy Subscale of the Self-Efficacy Scale Related to Minors. Notably, the Rosenberg Self-Esteem Scale, the Emotion Scale of the Coping Inventory for Stressful Situations, and the UCLA Loneliness Scale were strongly inter-correlated and showed the same correlation pattern with other variables.

[insert Table 4 around here] 
A number of socio-demographic variables and social desirability were also linked to stigma and outcome variables (e.g., people who are more educated report less emotional coping and less fear of discovery), confounding the link between them. To assess the effects of stigma on each of our independent variables while statistically controlling for these potential confounds, we conducted hierarchical regression analyses with socio-demographic variables, social desirability, and type of pedophilia (i.e., exclusive vs. non-exclusive) entered in block one, and stigma variables in block two (perceived social distance and fear of discovery, see Table 5 and 6 for results). The first set of predictors (specifically, age, relationship status, and/or social desirability) was significant only for the Fear of Negative Evaluation-5 and Emotion Subscale of the Coping Inventory for Stressful Situations. Stigma variables significantly explained between 7\% (Emotion Subscale of the Coping Inventory for Stressful Situations) and 24\% (Brief-Symptom-Inventory-53) of variance for emotional functioning $(p s<.05)$ above and beyond the predictors from the first block. For social functioning (UCLA Loneliness Scale), adding the stigma variables to the set of initial predictors lead to a significant increase of $19 \%$ in explained variance. Neither the variables in the first block nor the second block were significant predictors for cognitive distortions (Bumby Child Molest Scale and Coping Self-Efficacy Subscale of the Self-Efficacy Scale Related to Minors) and motivation to seek therapy (with the exception of social desirability, which predicted higher coping self-efficacy). Fear of discovery was significantly negatively linked to social and emotional functioning. Finally, perceived social distance was associated with less fear of negative evaluation - which was contrary to the hypothesized direction of this link. As binary correlations showed perceived social distance to be significantly linked to fear of discovery, but not to fear of negative evaluation $(r=-.13$, n.s. $)$, it can be concluded that perceived social distance acted as a suppressor variable between fear of discovery and fear of negative evaluation. The already high correlation between fear of discovery and fear 
of negative evaluation was therefore even higher than directly observed $(r=.43)$ when controlling for perceived social distance.

[insert Table 5 and 6 around here]

\section{DISCUSSION}

Within our framework for the effects of stigma-related stress among people with pedophilia, we have combined findings from stigma research on other groups (Rusch, Angermeyer, \& Corrigan, 2005), positions from the Minority Stress Theory (Meyer, 2003) and etiological theories from sexual offending research (T. Ward \& Beech, 2006) to create a systematic set of assumptions about possible stigma consequences for people with pedophilia. We have gathered empirical data to explore the hypothetical links between societal attitudes towards this group (as perceived by them), psychological functioning, and risk factors for child sexual abuse. Some of our analyses supported the hypotheses from our framework while others were not in line with our previous assumptions. Results indicated that fear of being discovered as a person with pedophilia was indeed negatively associated with social and emotional functioning, but neither with cognitive variables nor the motivation to seek therapy. The expected positive link between perceived social distance and child sexual abuse risk factors could not be shown (but note that there were marginally significant associations between perceived social distance and previous sexual offending against children, $r=.19, p=$ .06 , and therapy motivation, $r=-.18, p=.07)$.

\section{Stigma-Related Stress among People with Pedophilia}

The people with pedophilia who participated in this study $-73 \%$ of whom have never been convicted for child sexual abuse or child pornography offenses - reported high levels of perceived social distance. Comparing participants' responses with results from a large public stigma survey from Germany (Jahnke et al., 2015), people with pedophilia appear to overestimate the already high level of discrimination intention towards their group in the 
population. For instance, a majority believed that most German people would agree to incarcerate people with pedophilia in the absence of a crime, while in fact this seems to be a minority opinion (Jahnke et al., 2015). Consequently, many individuals in our sample experienced fears of their sexual interests being discovered by others, prompting a large number of participants to employ strategies to avoid suspicion (e.g., by not talking about pedophilia-related topics with others). People with pedophilia may therefore lack opportunities to verify their assumptions about how the majority actually perceives them, but instead base their conclusions on their experiences with a small, but possibly very vocal, number of people or media expressing high levels of stigmatizing attitudes. Considering that negative outcomes are associated with the individual's perception of stigma, this observation may pose a chance to reduce stigma-related effects by informing people with pedophilia about their overestimation of public stigma. Nevertheless, actual public stigma is still high (Jahnke et al., 2015), and punitive attitudes towards people with pedophilia have been found to be positively related to social desirability (Imhoff, 2015), indicating that extreme stances towards this group are perceived as the social norm that individuals need to follow in order to make a good impression.

Contrary to studies finding an association between awareness of stigma and impaired functioning (e.g., Corrigan et al., 2006), perceived social distance in this survey was not found to predict cognitive distortions, emotional or social functioning, or motivation to seek therapy. Just because people with pedophilia acknowledge public stigma they do not necessarily believe or internalize it (see also Rusch et al., 2005). According to our results, fear of discovery is a more appropriate indicator for how much people with pedophilia are affected by public stigma.

\section{Social and Emotional Functioning}


With regard to social and emotional functioning, we found that people in our sample presented more deficits than people from the general population (with the exception of selfesteem, fear of negative evaluation, and emotion-focused coping), but at the same time higher functioning than participants from clinical and/or forensic samples of people with pedophilia. Moreover, we could show that the more people with pedophilia experienced fear that others may find out about their sexual interests, the more emotional and social problems are reported, even when controlling for potential confounds like social desirability, educational level, and age. This is in line with the assumptions from our framework, which has been informed by similar experiences of LGB people (Meyer, 2003). Therefore, similar to these sexual minority groups, higher rates of mental disorders among people with pedophilia may result from, or be exacerbated by, the stressful experience of belonging to a stigmatized group. The more people with pedophilia in our sample experienced fear of discovery, the more likely they were to indicate other factors that are hypothesized to be precursors of psychological dysfunctions (such as emotional coping and lower self-esteem, see Hatzenbuehler, 2009). For social functioning, participants with higher scores of fear of discovery also tended to report more problems related to loneliness, which corresponds to results from other sexual minority groups (Westefeld, Maples, Buford, \& Taylor, 2001).

\section{Cognitive Distortions}

Our framework also postulates a link between stigma-related stress and cognitive distortions that could not be confirmed in this research. One explanation could be that individuals with a sexual interest in children who belong to online communities or social circles of other people with pedophilia have found a way to overcome their "isolated minority syndrome" (Fog, 1992) and have learned appropriate ways to deal with their sexuality. In any case, people with pedophilia in this study appeared to have enough critical distance from common stereotypes about themselves to not lose their expectations of control and 
competence with regard to refraining from sexual acts with children. Another limitation is the applicability of the Bumby Molest Scale which was designed for offender populations and may have produced reactance in some participants. Given these restrictions, there were, however, meaningful correlations between scores on the Bumby scale and various other variables (e.g., previous convictions), supporting convergent validity of this scale even in this community sample.

\section{Motivation to Seek Therapy}

Our initial assumptions regarding the links between stigma-related stress and the motivation to pursue therapy were not confirmed empirically. Although about half of the participants appeared to be hesitant about talking to mental health practitioners (and doubted that practitioners were capable to understand their problems), their willingness to confide in a physician or psychotherapist does not seem to depend on fear of discovery or perceived social distance. More research is needed to elucidate whether this holds true for people with pedophilia with higher levels of psychopathology or living in countries with stricter reporting laws as well.

\section{Limitations and Outlook}

There are a number of factors that limit the validity and generalizability of the reported results. First of all, due to the correlational design, there is no proof for a causal relationship between stigma-related stress and the variables tested in this article. Longitudinal designs are needed to clarify the temporal order of the relationship between stigma-related stress and outcome variables such as loneliness or self-esteem. Also, because all measures were given in the same order to each participant, order effects might have occurred.

Also, we did not include questions pertaining to actual experiences of stigma (e.g., threats of violence upon being discovered as having pedophilia). Although such events may not frequently occur among people with pedophilia, who mostly appear to take many 
precautions to keep their stigmatized identity a secret, they may nevertheless have a large impact on their lives. Hence, such experiences should be assessed in future studies in order to achieve a more complete picture of stigma-related stress among people with pedophilia.

Another important and novel aspect of the study is that the participants have been recruited from online communities instead of offender populations. Thus, we can provide the field with information about a target population whom we currently know very little about. This strategy, however, possibly entails a selection bias, as participants who volunteered for participation are likely to have different characteristics (e.g., higher education) than people with pedophilia who did not take part in the survey. Nevertheless, this is, to the best of the authors' knowledge, the first cross-sectional study to provide insight into how people with pedophilia experience and react to the stigma towards their sexual interests.

In summary, this research indicates that a number of assumptions derived from our framework appear to be valid and worthy of further consideration. Empirically testing an association between stigma-related stress and actual sexual offending risk among people with pedophilia, however, remains a difficult challenge. Due to the illegal nature of such acts, honest responding is likely to be compromised even in settings with a high degree of anonymity (e.g., online surveys), as a failure to guard anonymity (e.g., if the server is hacked or law enforcement is pressing charges) could lead to substantial social and legal repercussions. As such limitations do not exist for convicted offenders with pedophilia, researchers may test whether stigma-related variables (e.g., fear of discovery or actual experiences of discrimination) have any predictive value for sexual recidivism. For those who do not offend or have not been detected offending, researchers should focus on minimizing the potential risk of open self-reports, which may also include negotiating a guarantee of nonprosecution from law enforcement authorities despite incriminatory information that may be obtained during the survey. Also, authors of future surveys might consider including 
questions that are not legally relevant, but could be used as proxies for actual offending (e.g., "I would watch child pornography, if I knew that I would not be prosecuted") and estimating the degree of honest responding by comparing reported offense rates with offense rates obtained by using randomized response techniques (Hoffmann, Schmidt, Waubert de Puiseau, \& Musch, 2014; Warner, 1965).

Regardless of whether future research substantiates the hypotheses that stigma-related experiences contribute to sexual offending risk, the severe stigmatization of people with pedophilia does have a number of implications for clinical health management practices. Mental health care professionals should be aware of the negative public reactions towards people with pedophilia (that clients may perceive as being even more hostile than they actually are), which may in turn trigger fears to be discovered. Devising strategies to help the person cope with the stigma ( Williams, Moore, Adshead, McDowell, \& Tapp, 2011) should be an adjunctive therapy goal that is likely to have at least a positive indirect influence on dynamic child sexual abuse risk factors (Whitaker et al., 2008) such as low self-esteem, ineffective coping, and social isolation (but note that these efforts should remain an important element of clinical practice even in the case that stigma-related stress is not discovered to increase sexual offense rates).

Furthermore, our findings emphasize that there exists a subgroup of people with pedophilia with considerably less problems regarding the psychological functioning deficits usually found among clinical and/or forensic samples. This discovery could contribute to a reframing of overly pessimistic attitudes concerning this group, as they are not uncommon among clinicians and researchers (e.g., T. Ward \& Siegert, 2002, who wrote about "pure pedophiles" that this group "is likely to exhibit a multitude of offence-related deficits [i.e. cognitive distortions about sex with children, impaired attachment, emotion regulation, and coping deficits]," p. 339). Note, however, that our sample is not representative for people 
with pedophilia in general and that samples drawn from other sources potentially present different characteristics.

In light of our findings, researchers and practitioners should, nevertheless, be aware that elevated rates of psychopathology or other social or emotional deficits might, at least in part, be due to public stigma and the high levels of stress and anxiety that are associated with it. As this most probably does not only apply to people with pedophilia, de-stigmatization of mental illness or sexual minority interests in general, should remain on the agenda of any humanitarian society. 


\section{REFERENCES}

Abel, G. G., Becker, J. V., \& Cunningham-Rathner, J. (1984). Complications, consent, and cognitions in sex between children and adults. International Journal of Law and Psychiatry, 7, 89-103. doi: 10.1016/0160-2527(84)90008-6

Adiele, T., Davidson, C. M., Harlow, M. C., \& del Busto, E. (2011). Co-Morbid Mental Disorders in Incarcerated Paedophiles. Sexual Offender Treatment, 6(2).

Ahmad, S., \& Bhugra, D. (2010). Homophobia: an updated review of the literature. Sexual and Relationship Therapy, 25, 447-455. doi: 10.1080/14681994.2010.515206

Alanko, K., Haikio, J., Laiho, M., Jahnke, S., \& Santtila, P. (2014). Attitudes and knowledge to treat potential child sexual offenders among Finnish health care professionals. Manuscript submitted for publication.

American Psychiatric Association. (2013). Diagnostic and statistical manual of mental disorders (5th ed.). Arlington, VA: American Psychiatric Publishing.

Angermeyer, M. C., \& Dietrich, S. (2006). Public beliefs about and attitudes towards people with mental illness: A review of population studies. Acta Psychiatrica Scandinavica, 113, 163-179. doi: 10.1111/j.1600-0447.2005.00699.x

Baumeister, R. F., \& Leary, M. R. (1995). The need to belong: Desire for interpersonal attachments as a fundamental human motivation. Psychological Bulletin, 117, 497529. doi: 10.1037/0033-2909.117.3.497

Beier, K. M., Ahlers, C. J., Goecker, D., Neutze, J., Mundt, I. A., Hupp, E., \& Schaefer, G. A. (2009). Can pedophiles be reached for primary prevention of child sexual abuse? First results of the Berlin Prevention Project Dunkelfeld (PPD). Journal of Forensic Psychiatry \& Psychology, 20, 851-867. doi: 10.1080/14789940903174188 
Bilsky, W., \& Hosser, D. (1998). Soziale Unterstützung und Einsamkeit: Psychometrischer Vergleich zweier Skalen auf Basis einer bundesweiten Repräsentativbefragung. Zeitschrift für Differentielle und Diagnostische Psychologie, 19(2), 130-144.

Bumby, K. M. (1996). Assessing the cognitive distortions of child molesters and rapists: Development and validation of the MOLEST and RAPE scales. Sexual Abuse: A Journal of Research and Treatment, 8, 37-54. doi: 10.1177/107906329600800105

Corrigan, P. W., Watson, A. C., \& Barr, L. (2006). The self-stigma of mental illness: Implications for self-esteem and self-efficacy. Journal of Social and Clinical Psychology, 25, 875-884. doi: 10.1521/jscp.2006.25.8.875

Crowne, D. P., \& Marlowe, D. (1960). A new scale of social desirability independent of psychopathology. Journal of Consulting Psychology, 24, 349-354. doi: $10.1037 / \mathrm{h} 0047358$

Derogatis, L. R., \& Savitz, K. L. (2000). The SCL-90-R and Brief Symptom Inventory (BSI) in primary care. In M. Maruish (Ed.), Handbook of psychological assessment in primary care settings (pp. 297-334). Mahwah, NJ, US: Lawrence Erlbaum Associates Publishers.

Derogatis, L. R., \& Spencer, M. S. (1982). The Brief Symptom Inventory (BSI): Administration, scoring, and procedures manual 1. Baltimore: Johns Hopkins University School of Medicine, Clinical Psychometrics Research Unit.

Dombert, B., Schmidt, A. F., Banse, R., Briken, P., Hoyer, J., Neutze, J., \& Osterheider, M. (2015). How common is males' sexual interest in prepubescent children? Manuscript submitted for publication.

Endler, N. S., \& Parker, J. D. A. (1990). Multidimensional assessment of coping: A critical evaluation. Journal of Personality and Social Psychology, 58, 844-854. doi: $10.1037 / / 0022-3514.58 .5 .844$ 
Feelgood, S., Cortoni, F., \& Thompson, A. (2005). Sexual coping, general coping and cognitive distortions in incarcerated rapists and child molesters. Journal of Sexual Aggression, 11, 157-170. doi: 10.1080/13552600500073657

Feldman, D. B., \& Crandall, C. S. (2007). Dimensions of mental illness stigma: What about mental illness causes social rejection? Journal of Social and Clinical Psychology, 26, 137-154. doi: 10.1521/jscp.2007.26.2.137

Ferring, D., \& Filipp, S.-H. (1996). Messung des Selbstwertgefühls: Befunde zu Reliabilität, Validität und Stabilität der Rosenberg-Skala. Diagnostica, 42, 284-292.

Finkelhor, D., \& Araji, S. (1986). Explanations of pedophilia: A four factor model. Journal of Sex Research, 22, 145-161. doi: 10.1080/00224498609551297

Fog, A. (1992). Paraphilias and therapy. Nordisk Sexologi 10(4), 236-242.

Franke, G. H. (2000). Brief Symptom Inventory von Derogatis (BSI). Göttingen: Hogrefe.

Geisheim, C., Hahlweg, K., Fiegenbaum, W., Frank, M., Schröder, B., \& von Witzleben, I. (2002). Das Brief Symptom Inventory (BSI) als Instrument zur Qualitätssicherung in der Psychotherapie. Diagnostica, 48, 28-36.

Goffman, E. (1963). Stigma: Notes on the management of spoiled identity. New York: Touchstone.

Gonsior, K. (2002). Erfassung von kognitiven Verzerrungen und Opferempathie bei Sexualstraftätern (Unpublished diploma thesis). Technische Universität Dresden, Dresden.

Hall, R. C. W., \& Hall, R. C. W. (2007). A profile of pedophilia: Definition, characteristics of offenders, recidivism, treatment outcomes, and forensic issues. Mayo Clinic Proceedings, 82, 457-471. doi: 10.4065/82.4.457 
Hatzenbuehler, M. L. (2009). How does sexual minority stigma "get under the skin"? A psychological mediation framework. Psychological Bulletin, 135, 707-730. doi: $10.1037 / \mathrm{a} 0016441$

Hatzenbuehler, M. L., Phelan, J. C., \& Link, B. G. (2013). Stigma as a fundamental cause of population health inequalities. American Journal of Public Health, 103, 813-821. doi: 10.2105/AJPH.2012.301069

Hoffmann, A., Schmidt, A. F., Waubert de Puiseau, B., \& Musch, J. (2014). On the comprehensibility and perceived privacy protection of indirect questioning techniques. Manuscript submitted for publication.

Holt, T. J., Blevins, K. R., \& Burkert, N. (2010). Considering the pedophile subculture online. Sexual Abuse: A Journal of Research and Treatment, 22, 3-24. doi: $10.1177 / 1079063209344979$

Hoyer, J., Kunst, H., \& Schmidt, A. (2001). Social phobia as a comorbid condition in sex offenders with paraphilia or impulse control disorder. Journal of Nervous and Mental Disease, 189, 463-470. doi: 0022-3018/01/1897-463

Imhoff, R. (2015). Punitive attitudes against pedophiles or persons with sexual interest in children: Does the label matter? Archives of Sexual Behavior, 44, 35-44. doi:10.3389/fpsyg.2014.00085

Jahnke, S., \& Hoyer, J. (2013). Stigmatization of people with pedophilia: A blind spot in stigma research International Journal of Sexual Health, 25, 169-184. doi: $10.1080 / 19317611.2013 .795921$

Jahnke, S., Imhoff, R., \& Hoyer, J. (2015). Stigmatization of people with pedophilia: Two comparative surveys. Archives of Sexual Behavior, 44, 21-34. doi: 10.1007/s10508014-0312-4 
Jahnke, S., Philipp, K., \& Hoyer, J. (2014). Stigmatizing attitudes towards people with pedophilia and their malleability among psychotherapists in training. Child Abuse \& Neglect. doi: 10.1016/j.chiabu.2014.07.008

Kälin, W. (1995). Deutsche 24-Item Kurzform des „, Coping Inventory for Stressful Situations" (CISS) von N. S. Endler \& J. D. A. Parker. Basierend auf der Übersetzung von N. Semmer, F. Tschan, \& V. Schade (unveröffentlichter Fragebogen). Institut für Psychologie, Universität Bern.

Kays, K., Gathercoal, K., \& Buhrow, W. (2012). Does survey format influence selfdisclosure on sensitive question items? Computers in Human Behavior, 28, 251-256. doi: 10.1016/j.chb.2011.09.007

Kemper, C. J., Lutz, J., \& Neuser, J. (2012). Konstruktion und Validierung einer Kurzform der Skala Angst vor negativer Bewertung (SANB-5). Klinische Diagnostik und Evaluation, 4, 343-360.

Lane, J. D., \& Wegner, D. M. (1995). The cognitive consequences of secrecy. Journal of Personality and Social Psychology, 69, 237-253. doi: 10.1037//0022-3514.69.2.237

Leue, A., Borchard, B., \& Hoyer, J. (2004). Mental disorders in a forensic sample of sexual offenders. European Psychiatry, 19, 123-130. doi: 10.1016/j.eurpsy.2003.08.001

Link, B. G., Struening, E. L., Rahav, M., Phelan, J. C., \& Nuttbrock, L. (1997). On stigma and its consequences: Evidence from a longitudinal study of men with dual diagnoses of mental illness and substance abuse. Journal of Health and Social Behavior, 38, 177-190. doi: $10.2307 / 2955424$

Mann, R. E., Hanson, R. K., \& Thornton, D. (2010). Assessing risk for sexual recidivism: Some proposals on the nature of psychologically meaningful risk factors. Sexual Abuse: A Journal of Research and Treatment, 22, 191-217. doi: $10.1177 / 1079063210366039$ 
Marshall, W. L., Serran, G. A., \& Cortoni, F. A. (2000). Childhood attachments, sexual abuse, and their relationship to adult coping in child molesters. . Sexual Abuse: A Journal of Research and Treatment, 12, 17-26. doi: 10.1177/107906320001200103

McCartan, K. F. (2010). Student/trainee-professional implicit theories of paedophilia. Psychology Crime \& Law, 16, 265-288. doi: 10.1080/10683160802614144

Meyer, I. H. (2003). Prejudice, social stress, and mental health in lesbian, gay, and bisexual populations: Conceptual issues and research evidence. Psychological Bulletin, 129, 674-697. doi: 10.1037/0033-2909.129.5.674

Neuser, J. (2003). Skala „Angst vor negativer Bewertung“ (SANB). In J. Hoyer \& J. Margraf (Eds.), Grundlagen und Testverfahren: Angstdiagnostik (pp. 280-283). Berlin: Springer.

Neutze, J., Grundmann, D., Scherner, G., \& Beier, K. M. (2012). Undetected and detected child sexual abuse and child pornography offenders. International Journal of Law and Psychiatry, 35, 168-175. doi: 10.1016/j.ijlp.2012.02.004

Neutze, J., Seto, M. C., Schaefer, G. A., Mundt, I. A., \& Beier, K. M. (2011). Predictors of child pornography offenses and child sexual abuse in a community sample of pedophiles and hebephiles. Sexual Abuse: A Journal of Research and Treatment, 23, 212-242. doi: $10.1177 / 1079063210382043$

Okami, P., \& Goldberg, A. (1992). Personality correlates of Pedophilia: Are they reliable indicators? Journal of Sex Research, 29, 297-328.

Pachankis, J. E. (2007). The psychological implications of concealing a stigma: A cognitiveaffective-behavioral model. Psychological Bulletin, 133, 328-345. doi: 10.1037/00332909.133.2.328 
Pithers, W. D., Kashima, K. M., Cumming, G. F., Beal, L. S., \& Buell, M. M. (1988). Relapse prevention of sexual aggression. Annals of the New York Academy of Sciences, 528, 244-260. doi: 10.1111/j.1749-6632.1988.tb50868.x

Rambow, J., Elsner, K., Feelgood, S., \& Hoyer, J. (2008). Einstellungen zum Kindesmissbrauch: Untersuchungen mit der Bumby Child Molest Scale bei Missbrauchs-und Gewalttätern. Zeitschrift für Sexualforschung, 21, 341-355. doi: $10.1055 / \mathrm{s}-0028-1098723$

Raymond, N. C., Coleman, E., Ohlerking, F., Christenson, G. A., \& Miner, M. (1999). Psychiatric comorbidity in pedophilic sex offenders. American Journal of Psychiatry, $156,786-788$.

Rosenberg, M. (1965). Society and the adolescent self-image. Princeton, NJ: Princeton University Press.

Rusch, N., Angermeyer, M. C., \& Corrigan, P. W. (2005). Mental illness stigma: Concepts, consequences, and initiatives to reduce stigma. European Psychiatry, 20, 529-539.

Russell, D., Peplau, L. A., \& Cutrona, C. E. (1980). The revised UCLA Loneliness Scale: concurrent and discriminant validity evidence. Journal of Personality and Social Psychology, 39, 472-480. doi: 10.1037/0022-3514.39.3.472

Russell, D. W. (1996). UCLA Loneliness Scale (Version 3): Reliability, validity, and factor structure. Journal of Personality Assessment, 66, 20-40. doi: DOI 10.1207/s15327752jpa6601_2

Schaefer, G. A., Mundt, I. A., Feelgood, S., Hupp, E., Neutze, J., Ahlers, C. J., . . . Beier, K. M. (2010). Potential and Dunkelfeld offenders: Two neglected target groups for prevention of child sexual abuse. International Journal of Law and Psychiatry, 33, 154-163. doi: 10.1016/j.ijlp.2010.03.005 
Schmidt, A. F., Mokros, A., \& Banse, R. (2013). Is pedophilic sexual preference continuous? A taxometric analysis based on direct and indirect measures. Psychological Assessment, 25(4), 1146-1153. doi: 10.1037/A0033326

Seto, M. C. (2008). Pedophilia and sexual offending against children: Theory, assessment, and intervention. Washington, DC: American Psychological Association.

Seto, M. C. (2012). Is pedophilia a sexual orientation? Archives of Sexual Behavior, 231-236.

Smart, L., \& Wegner, D. M. (2000). The hidden costs of hidden stigma. In T. F. Heatherton, R. E. Kleck, M. R. Hebl \& J. G. Hull (Eds.), The social psychology of stigma (pp. 220-242). New York: Guilford Press.

Smolenski, D. J., Stigler, M. H., Ross, M. W., \& Rosser, B. R. S. (2011). Direct and indirect associations between internalized homonegativity and high-risk sex. Archives of Sexual Behavior, 40, 785-792. doi: 10.1007/s10508-010-9705-1

Stiels-Glenn, M. (2010). The availability of outpatient psychotherapy for paedophiles in Germany. Recht \& Psychiatrie, 28, 74-80.

Stöber, J. (1999). Die Soziale-Erwünschtheits-Skala-17 (SES-17): Entwicklung und erste Befunde zu Reliabilität und Validität. Diagnostica, 45, 173-177. doi: 10.1026//00121924.45.4.173

Vogel, D. L., \& Wade, N. G. (2009). Stigma and help-seeking. Psychologist, 22, 20-23. Ward, P., Clark, T., Zabriskie, R., \& Morris, T. (2012). Paper/pencil versus online data collection: An exploratory study. Journal of Leisure Research, 44(4), 507-530.

Ward, T., \& Beech, A. (2006). An integrated theory of sexual offending. Aggression and Violent Behavior, 11, 44-63. doi: 10.1016/j.avb.2005.05.00

Ward, T., \& Keenan, T. (1999). Child molesters' implicit theories. Journal of Interpersonal Violence, 14, 821-838. doi: 10.1177/088626099014008003 
Ward, T., \& Siegert, R. J. (2002). Toward a comprehensive theory of child sexual abuse: A theory knitting perspective. Psychology Crime \& Law, 8, 319-351. doi: $10.1080 / 1068316021000054274$

Warner, S. L. (1965). Randomized-Response - a Survey Technique for Eliminating Evasive Answer Bias. Journal of the American Statistical Association, 60(309), 63-69. doi: Doi $10.2307 / 2283137$

Watson, D., \& Friend, R. (1969). Measurement of social-evaluative anxiety. Journal of Consulting and Clinical Psychology, 33, 448-457. doi: 10.1037/H0027806

West, D. (2000). Paedophilia: Plague or panic? Journal of Forensic Psychiatry, 11, 511-531. doi: 10.1080/09585180010002669

Westefeld, J. S., Maples, M. R., Buford, B., \& Taylor, S. (2001). Gay, lesbian, and bisexual college students: The relationship between sexual orientation and depression, loneliness, and suicide. Journal of College Student Psychotherapy, 15(3), 71-82. doi: 10.1300/J035v15n03_06

Whitaker, D. J., Le, B., Hanson, R. K., Baker, C. K., McMahon, P. M., Ryan, G., . . Rice, D. D. (2008). Risk factors for the perpetration of child sexual abuse: A review and metaanalysis. Child Abuse \& Neglect, 32(5), 529-548. doi: DOI 10.1016/j.chiabu.2007.08.005

Williams, A., Moore, E., Adshead, G., McDowell, A., \& Tapp, J. (2011). Including the excluded: High security hospital user perspectives on stigma, discrimination, and recovery. The British Journal of Forensic Practice, 13(3), 197-204. doi: $10.1108 / 14636641111157841$

Wilson, G., \& Cox, D. (1983). The child lovers: A study of paedophiles in society. London: Peter Owen Publishers. 


\section{Public stigma}

- Agreement with stereotypes (e.g., “All people with pedophilia are child molesters!”)

- Negative affective response: fear, anger, reduced pity

- Social distance

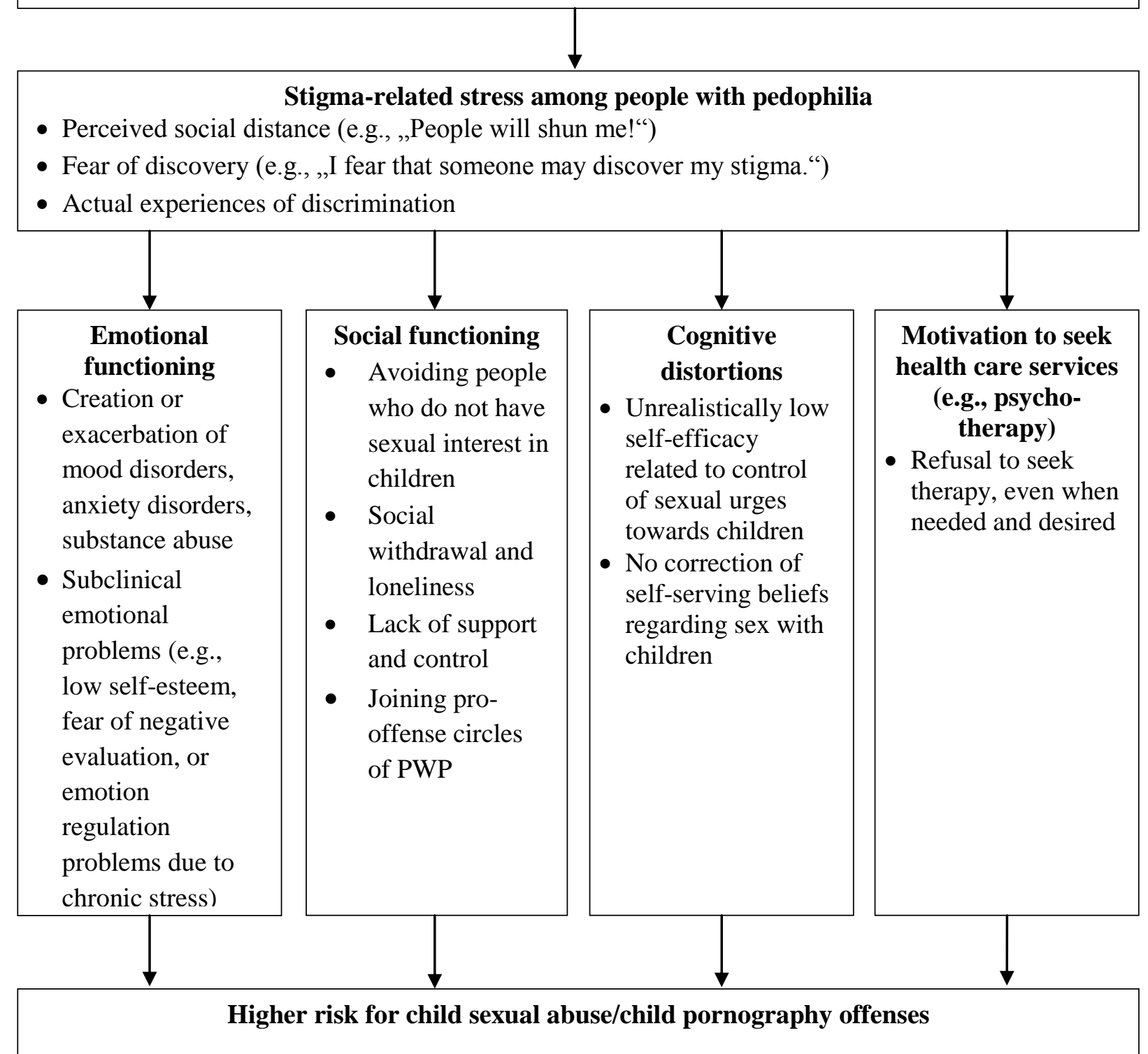

Figure 1 Overview of the framework for the effects of stigma-related stress among people with pedophilia

Note. Arrows represent hypothetic causal associations 
Table 1. Prevalence of Axis-I disorders and related mental health factors among people with pedophilia (study overview)

\begin{tabular}{|c|c|c|}
\hline Study & Sample & Results concerning mental health \\
\hline Hoyer, Kunst \& Schmidt, & 23 incarcerated sex offenders & $53.3 \%$ social phobia (lifetime, groups were pooled for the analysis, \\
\hline$(2001)$ & sex offenders with sexual sadism & questionnaires for social anxiety) \\
\hline Leue, Borchard, and & 30 incarcerated sex offenders & $93 \%$ comorbid axis I or personality disorder, $73 \%$ any anxiety disorder, \\
\hline Hoyer (2004) & $\begin{array}{l}\text { with a paraphilia (18 with } \\
\text { pedophilia) }\end{array}$ & $\begin{array}{l}57 \% \text { any substance use disorder, } 30 \% \text { mood disorder; among anxiety } \\
\text { disorders, social phobia ( } 38 \%) \text { was most common ( } 53 \% \text {, all lifetime) }\end{array}$ \\
\hline Raymond et al. (1999) & with pedophilia & $\begin{array}{l}(64.0 \%) \text { and substance disorders }(60.0 \%) \text { being most prevalent; among } \\
\text { anxiety disorders, social phobia }(38 \%) \text { was most common }\end{array}$ \\
\hline \multirow[t]{2}{*}{ Schaefer et al. (2010) } & $\begin{array}{l}160 \text { nonincarcerated people with } \\
\text { pedophilia from the Berlin }\end{array}$ & $\begin{array}{l}51.5 \% \text { of undetected offenders with pedophilia have sought professional } \\
\text { help in the past, } 38.1 \% \text { of nonoffenders with pedophilia have sought }\end{array}$ \\
\hline & Prevention Project Dunkelfeld & professional help in the past \\
\hline
\end{tabular}


Table 2. Items and descriptive overview ( $M, S D$, percentage of item agreement, Cronbach's $\alpha)$ of newly developed questionnaires

\begin{tabular}{|c|c|c|c|}
\hline Scale (item) & $M$ & $S D$ & $\begin{array}{l}\text { Agree } \\
(\%)\end{array}$ \\
\hline Perceived Social Distance Scale $(\alpha=.84)$ & 4.81 & 0.91 & - \\
\hline Would have these persons as friends. & 0.72 & 1.20 & 4.81 \\
\hline Would accept these persons in my neighborhood. & 0.63 & 0.89 & 1.92 \\
\hline Would accept these persons as colleagues at work. & 0.91 & 1.07 & 3.85 \\
\hline Would talk to them. & 1.64 & 1.22 & 7.69 \\
\hline These persons should be incarcerated. & 4.81 & 1.32 & 83.65 \\
\hline These persons should better be dead. & 3.96 & 1.54 & 63.46 \\
\hline Fear of Discovery Scale $\left(\mathbf{N}=100^{*}\right)(\alpha=.89)$ & 3.97 & 1.31 & - \\
\hline I'm afraid that others may discover my secret. & 5.16 & 1.41 & 83.65 \\
\hline It scares me that others might know about my secret. & 4.86 & 1.59 & 81.73 \\
\hline When thinking about others discovering my secret I become nervous and feel my heart beat rise. & 3.96 & 1.95 & 60.58 \\
\hline The thought of others finding out about my secret causes physical discomfort. & 3.82 & 1.91 & 58.65 \\
\hline I worry a lot about what will happen if others find out about my secret. & 3.88 & 1.92 & 56.73 \\
\hline I cannot shake off thoughts about the possibility of my secret being discovered. & 2.95 & 1.94 & 41.35 \\
\hline I avoid talking about subjects that are related to my secret. & 3.40 & 2.11 & 50.00 \\
\hline I try to act in a way that no one can find out that I carry a secret. & 4.28 & 1.87 & 68.27 \\
\hline It is stressful for me to keep my secret. & 3.33 & 1.94 & 46.15 \\
\hline Having this secret is distressing to me. & 4.03 & 1.96 & 62.50 \\
\hline Therapy Motivation Scale $(\alpha=.84)$ & 2.91 & 1.68 & - \\
\hline I would confide in a health care professional. & 3.36 & 2.14 & 57.69 \\
\hline I would seek professional help even if it means I have to talk about my sexual interests in children to a stranger. & 3.21 & 2.22 & 51.92 \\
\hline I think that a health care professional will understand my problems. & 2.61 & 2.03 & 35.58 \\
\hline I think that it is very likely that a health care professional reacts negatively when I reveal my sexual interests in children. & 3.55 & 1.77 & 55.77 \\
\hline
\end{tabular}

Note. All scales range from 0 to 6.

* Four participants reported that they did not keep their pedophilia a secret from anybody and therefore, did not complete the Fear of Discovery Scale 
Table 3. Reliability and outcome levels as compared to other reference samples

\begin{tabular}{|c|c|c|c|c|c|c|c|}
\hline & \multirow[b]{2}{*}{$M$} & \multirow[b]{2}{*}{$S D$} & \multicolumn{3}{|l|}{ Comparison group } & \multirow{2}{*}{$\begin{array}{l}\text { test statistics } \\
t(d f)\end{array}$} & \multirow{2}{*}{$\begin{array}{l}\text { Effect } \\
\text { size }\end{array}$} \\
\hline & & & Sample (reference) & $M$ & $S D$ & & \\
\hline \multirow[t]{2}{*}{$\begin{array}{l}\text { Brief-Symptom Inventory- } \\
53^{3}(\alpha=.97)\end{array}$} & 0.90 & 0.70 & $\begin{array}{l}N=46 \text { patients with pedophilia from Berlin Prevention Project } \\
\text { Dunkelfeld (Beier et al., 2013) }\end{array}$ & 0.96 & 0.56 & $0.51(148)$ & 0.09 \\
\hline & & & 300 members of the average population (Franke, 2000) & 0.28 & 0.23 & $13.42(402)^{* *}$ & 1.19 \\
\hline $\begin{array}{l}\text { Fear of Negative Evaluation } \\
\text { Scale- } 5^{2}(\alpha=.88)\end{array}$ & 1.18 & 0.78 & $\begin{array}{l}N=2603 \text { members of the general population in Germany } \\
\text { (Kemper, Lutz, \& Neuser, 2012) }\end{array}$ & 1.14 & 0.72 & $0.55(2705)$ & 0.05 \\
\hline $\begin{array}{l}\text { Rosenberg Self-Esteem } \\
\operatorname{Scale}^{3}(\alpha=.89)\end{array}$ & 2.63 & 0.88 & 92 members of ad-hoc sample (Ferring \& Filipp, 1996) & 2.29 & 0.44 & $3.35(194)^{* *}$ & 0.49 \\
\hline \multirow{2}{*}{$\begin{array}{l}\text { Subscale Emotion-Oriented } \\
\text { Coping from the Coping } \\
\text { Inventory for Stressful } \\
\text { Situations }^{3}(\alpha=.84)\end{array}$} & 1.63 & 0.80 & $\begin{array}{l}N=505 \text { young Swiss professionals (Kälin, 1995), statistics } \\
\text { retrieved from (Beier et al., 2013) }\end{array}$ & 1.89 & 0.68 & $3.44(607)^{* *}$ & 0.35 \\
\hline & & & $\begin{array}{l}N=46 \text { patients with pedophilia from Berlin Prevention Project } \\
\text { Dunkelfeld (Beier et al., 2013) }\end{array}$ & 2.18 & 0.67 & $4.07(148)^{* *}$ & 0.75 \\
\hline $\begin{array}{l}\text { UCLA Loneliness Scale }{ }^{3} \\
(\alpha=.91)\end{array}$ & 1.88 & 0.95 & $\begin{array}{l}N=3284 \text { members of the general population in Germany (Bilsky } \\
\& \text { Hosser, 1998) }\end{array}$ & 1.01 & 0.95 & $9.19(3386)^{* *}$ & 0.92 \\
\hline $\begin{array}{l}\text { Bumby Child Molest Scale }{ }^{3} \\
(\alpha=.92)\end{array}$ & 1.47 & 0.50 & $\begin{array}{l}N=18 \text { incarcerated child sexual abusers with pedophilia in } \\
\text { Germany (Borchers, 2007) }\end{array}$ & 1.94 & 0.56 & $3.62(120)^{* *}$ & 0.89 \\
\hline \multirow{2}{*}{$\begin{array}{l}\text { Coping Self-Efficacy } \\
\text { Subscale of the Self- } \\
\text { Efficacy Scale Related to } \\
\text { Minors }^{2}(\alpha=.96)\end{array}$} & 2.09 & 0.81 & $\begin{array}{l}N=196 \text { undetected child sex offenders with pedophilia or } \\
\text { hebephilia from the Berlin Prevention Project Dunkelfeld (Neutze, } \\
\text { Grundmann, Scherner, \& Beier, 2012) }\end{array}$ & 0.95 & 0.63 & $13.47 * *(298)$ & 1.57 \\
\hline & & & $\begin{array}{l}N=149 \text { detected child sex offenders with pedophilia or hebephilia } \\
\text { from the Berlin Prevention Project Dunkelfeld (Neutze et al., } \\
\text { 2012) }\end{array}$ & 0.89 & 0.70 & $12.57 * *(251)$ & 1.59 \\
\hline $\begin{array}{l}\text { Social Desirability Scale- } \\
17^{1}(\alpha=.74)\end{array}$ & 0.44 & .21 & $N=91$ psychology students (Stöber, 1999) & .37 & 0.48 & 1.35 (193) & 0.19 \\
\hline
\end{tabular}

Note. $N=104 . * p<.05 ; * * p<.01,{ }^{1}$ scale ranges from 0 to $1,{ }^{2}$ scale ranges from 0 to $3,{ }^{3}$ scale ranges from 0 to 5 
Table 4. Overview of intercorrelations (two-tailed, $N=104$ )

\begin{tabular}{|c|c|c|c|c|c|c|c|c|c|c|c|c|c|c|c|}
\hline Scale & 1 & $2^{a}$ & 3 & 4 & 5 & 6 & 7 & 8 & 9 & 10 & 11 & 12 & 13 & 14 & 15 \\
\hline \multicolumn{16}{|l|}{$1 \mathrm{PSDS}$} \\
\hline $2 \mathrm{FODS}^{\mathrm{a}}$ & $.24 *$ & & & & & & & & & & & & & & \\
\hline 3 age & -.05 & -.12 & & & & & & & & & & & & & \\
\hline 4 education $^{b}$ & -.09 & $-.22 *$ & $.22 *$ & & & & & & & & & & & & \\
\hline 5 relation. & .12 & .09 & $-.20 *$ & -.04 & & & & & & & & & & & \\
\hline 6 SDS-17 & -.06 & .05 & $-.23 *$ & .01 & $.20 *$ & & & & & & & & & & \\
\hline $\begin{array}{l}7 \text { pedophilia } \\
\text { type }^{\text {b }}\end{array}$ & .04 & -.13 & -.04 & .04 & $-.20 *$ & -.18 & & & & & & & & & \\
\hline 8 BSI- 53 & .06 & $.51 * *$ & -.18 & -.07 & -.16 & .10 & -.17 & & & & & & & & \\
\hline 9 FNE-5 & -.13 & $.43 * *$ & $-.32 * *$ & -.08 & -.14 & $.19 *$ & -.13 & $.53 * *$ & & & & & & & \\
\hline 10 RSES & -.16 & $-.32 * *$ & $.28 * *$ & .13 & .12 & -.17 & .00 & $-.59 * *$ & $-.65 * *$ & & & & & & \\
\hline $\begin{array}{l}11 \mathrm{COSI}- \\
\mathrm{ES}\end{array}$ & -.08 & $.32 * *$ & $-.30 * *$ & $-.22 *$ & -.04 & $.42 * *$ & -.18 & $.55 * *$ & $.60 * *$ & $-.57 * *$ & & & & & \\
\hline 12 UCLA LS & .12 & $.44 * *$ & -.13 & -.09 & $.25 * *$ & -.04 & -.07 & $.64 * *$ & $.43 * *$ & $-.54 * *$ & $.43 * *$ & & & & \\
\hline $\begin{array}{l}13 \text { Bumby } \\
\text { MS }\end{array}$ & .01 & -.02 & .13 & -.07 & -.04 & .13 & .04 & .08 & .17 & .00 & .15 & .01 & & & \\
\hline 14TMS & -.18 & -.01 & .03 & -.08 & -.17 & -.04 & -.17 & $-.20 *$ & -.05 & .11 & -.16 & $-.28 * *$ & -.19 & & \\
\hline 15 SESM-C & -.03 & -.15 & -.03 & .17 & -.01 & $-.21 *$ & -.05 & -.14 & -.15 & .09 & $-.26 * *$ & -.19 & $-.29 * *$ & .17 & \\
\hline 16 Convict. $^{b}$ & .19 & -.00 & .04 & -.04 & -.15 & .05 & .04 & .10 & .03 & -.15 & .17 & $.23 *$ & $.24 *$ & -.17 & $-.27 * *$ \\
\hline
\end{tabular}

Note. PSDS = Perceived Social Distance, FODS = Fear of Discovery Scale, education $(0=$ no Abitur, $1=$ Abitur, Abitur $=$ German higher education certificate), relation. $=$ relationship status $(1=$ none, $2=$ in relationship $)$, SDS- $17=$ Social Desirability Scale -17 , pedophilia type $(1=$ dominant attraction to children, 2 = no dominant attraction to children), BSI-53 = Brief Symptom Inventory-53, FNE-5 = Fear of Negative Evaluation-5, RSES $=$ Rosenberg Self-Esteem Scale, COSI- ES = Emotion Subscale of the Coping Inventory for Stressful Situations, UCLA LS = UCLA Loneliness Scale, Bumby MS = Bumby Molest Scale, TMS = Therapy Motivation Scale, SESM-C = Coping Self-Efficacy Subscale of the Self-Efficacy Scale Related to Minors, Convict. = convicted of child pornography offenses or child sexual abuse $(0=$ no conviction, $1=$ previous convictions $)$

${ }^{\mathrm{a}} N=100$, as four participants reported that they did not keep their pedophilia a secret from anybody and therefore, did not complete the Fear of Discovery Scale; ${ }^{b}$ Point-biserial correlations, ${ }^{*} p<.05 ; * * p<.01$ 
Table 5. Predictors of emotional functioning: Results of hierarchical multiple regression analysis

\begin{tabular}{|c|c|c|c|c|c|c|c|c|}
\hline & \multicolumn{2}{|c|}{$\begin{array}{l}\text { Brief Symptom } \\
\text { Inventory-53 }\end{array}$} & \multicolumn{2}{|c|}{$\begin{array}{l}\text { Fear of Negative } \\
\text { Evaluation- } 5^{\mathrm{b}}\end{array}$} & \multicolumn{2}{|c|}{$\begin{array}{l}\text { Rosenberg Self-Esteem } \\
\text { Scale }^{c}\end{array}$} & \multicolumn{2}{|c|}{$\begin{array}{l}\text { Emotion Subscale of the } \\
\text { Coping Inventory for } \\
\text { Stressful Situations }\end{array}$} \\
\hline & $\beta$ & $S E \beta$ & $\beta$ & $S E \beta$ & $\beta$ & $S E \beta$ & $\beta$ & $S E \beta$ \\
\hline \multicolumn{9}{|l|}{ Step 1} \\
\hline Age & -0.08 & 0.01 & $-0.20 *$ & 0.01 & 0.16 & 0.01 & -0.12 & 0.01 \\
\hline Relationship status & $-0.23^{*}$ & 0.18 & $-0.22 *$ & 0.20 & 0.13 & 0.26 & -0.16 & 0.21 \\
\hline Social Desirability & 0.06 & 0.32 & 0.15 & 0.35 & -0.16 & 0.45 & $0.38 * * *$ & 0.36 \\
\hline \multicolumn{9}{|l|}{ Step 2} \\
\hline $\begin{array}{l}\text { Perceived Social } \\
\text { Distance }\end{array}$ & -0.06 & 0.07 & $-0.24 * *$ & 0.08 & -0.11 & 0.10 & -0.11 & 0.08 \\
\hline Fear of Discovery & $0.53 * * *$ & 0.05 & $0.47 * * *$ & 0.05 & $-0.27 * *$ & 0.07 & $0.27 * *$ & 0.06 \\
\hline
\end{tabular}

\footnotetext{
Note. $N=100$

${ }^{\mathrm{a}} R^{2}=.10$ for Step $1(p=.08), \Delta R^{2}=.24$ for Step $2(p<.001)$

${ }^{\mathrm{b}} R^{2}=.16$ for Step $1(p<.01), \Delta R^{2}=.21$ for Step $2(p<.001)$

${ }^{\mathrm{c}} R^{2}=.10$ for Step $1(p=.06), \Delta R^{2}=.09$ for Step $2(p<.01)$

${ }^{\mathrm{d}} R^{2}=.29$ for Step $1(p<.001), \Delta R^{2}=.07$ for Step $2(p<.05)$

$\mathrm{e}=$ dummy coded

${ }^{*} p<.05 ; * * p<.01 ; * * * p<.001$.
} 
Table 6. Predictors of cognition, social functioning, and therapy motivation: Results of hierarchical multiple regression analysis

\begin{tabular}{|c|c|c|c|c|c|c|c|c|}
\hline & \multicolumn{2}{|c|}{$\begin{array}{l}\text { UCLA Loneliness } \\
\text { Scale }^{\mathrm{a}}\end{array}$} & \multicolumn{2}{|c|}{$\begin{array}{l}\text { Bumby Child Molest } \\
\text { Scale- }^{\text {b }}\end{array}$} & \multicolumn{2}{|c|}{$\begin{array}{l}\text { Coping Self-Efficacy } \\
\text { Subscale of the Self- } \\
\text { Efficacy Scale } \\
\text { Related to Minors }\end{array}$} & \multicolumn{2}{|c|}{$\begin{array}{l}\text { Therapy Motivation } \\
\text { Scale }^{\mathrm{d}}\end{array}$} \\
\hline & $\beta$ & $S E \beta$ & $\beta$ & $S E \beta$ & $\beta$ & $S E \beta$ & $\beta$ & $S E \beta$ \\
\hline \multicolumn{9}{|l|}{ Step 1} \\
\hline Age & -0.03 & 0.01 & $0.23 *$ & 0.00 & -0.17 & 0.01 & -0.04 & 0.02 \\
\hline Educational level $^{\mathrm{e}}$ & 0.00 & 0.19 & -0.10 & 0.11 & 0.18 & 0.17 & -0.10 & 0.37 \\
\hline Type of pedophilia ${ }^{\mathrm{e}}$ & -0.09 & 0.19 & 0.05 & 0.11 & -0.11 & 0.18 & -0.12 & 0.37 \\
\hline Relationship status $^{\mathrm{e}}$ & $-0.30 * *$ & 0.26 & -0.06 & 0.15 & 0.04 & 0.24 & 0.15 & 0.52 \\
\hline Social Desirability & -0.03 & 0.45 & 0.19 & 0.26 & $0.28 * *$ & 0.42 & -0.12 & 0.90 \\
\hline \multicolumn{9}{|l|}{ Step 2} \\
\hline Perceived Social Distance & -0.01 & 0.10 & -0.03 & 0.06 & 0.02 & 0.09 & -0.17 & 0.20 \\
\hline Fear of Discovery & $0.45 * * *$ & 0.07 & -0.01 & 0.04 & -0.14 & 0.06 & -0.01 & 0.14 \\
\hline
\end{tabular}

\footnotetext{
Note. $N=100$

${ }^{\mathrm{a}} R^{2}=.10$ for Step $1(p=.09), \Delta R^{2}=.19$ for Step $2(p<.001)$

${ }^{\mathrm{b}} R^{2}=.06$ for Step $1(p=.32), \Delta R^{2}=.00$ for Step $2(p=.96)$

${ }^{\mathrm{c}} R^{2}=.11$ for Step $1(p=.06), \Delta R^{2}=.02$ for Step $2(p=.39)$

${ }^{\mathrm{d}} R^{2}=.06$ for Step $1(p=.35), \Delta R^{2}=.03$ for Step $2(p=.22)$

$\mathrm{e}=$ dummy coded

${ }^{*} p<.05 ; * * p<.01 ; * * * p<.001$
} 